\title{
Memoria de una biblioteca, evocación de un padre
}

No tenía más de once años cuando por primera vez vislumbré al escritor que había en mi padre. Sería allá por el mes de Julio de 1977 cuando éste, no sin cierta ceremonia, me condujo hacia el salón principal de su biblioteca con el afán de encomendarme la delicada misión de la limpieza de lodos aquellos libros. Me parece recordar que protesté tan airadamente como me lo permilía el respeto paterno -es decir, no mucho- puesto que no sólo me parecía la biblioteca desmesuradamente grande, sino que creía ser víclima de una injusticia comparativa insostenible ya que ninguno de mis dos hermanos compartiría esta tarea. Sin embargo, pronto comprendi que no tenía alternativa: mi hermano menor eslaba disculpado por la edad, y mi hermana padecía de una grave alergia al polvo realmente insuperable, diagnosticada por el severo ojo clínico de mi madre y más importante aún-corroborada por anteriores y honestos intentos de emprender la limpieza. Para colmo de desgracia mi padre poseía una destreza en la argumentación práctica casi irrebatible y, claro está, ya de antemano había considerado y sopesado todas mis objeciones y disensiones. No tuve más remedio que asentir y asistir incrédulo a una pequeña demostración por parte de mi padre- un hombre totalmente incapacitado para cualquier tarea manual- sobre cómo debía realizar aquella tarea, lo que incluía una detallada enumeración de los instrumentos a utilizar, una elocuente demostración de la minuciosa mecánica de limpieza a emplear, así como la importancia de la colocación de los libros y la reparación de los volúmenes deleriorados. No terminaba de salir de mi asombro y me parecía que estaba fuera de sí. La fruición y el empeño que ponía en aquella demostración me convencieron de que esta tarea, a diferencia de otras encomendadas por mi padre, en las que siempre insistía en su cumplido y lustroso acabado, era una tarea comprensible sólo para un "fanático" de la literatura. Definitivamente, aquella fanática entrega no podía ser sino el síntoma de un escritor, de un hombre contagiado por la literatura: mis sospechas quedaron 
plenamente corroboradas cuando mi padre incluso sugirió que quizás en el futuro se pudiese inventariar loda la biblioleca.

Por entonces no supe ver en este encargo otra cosa que la capitulación y entrega de las mañanas de los siguientes dos meses de mis vacaciones escolares a la limpieza de los libros, ignorando que mi padre me encomendaba su más preciada posesión: aquella biblioteca que cuidaba como un tesoro. No fue él un hombre libresco, y pese a que su admiración por Borges era enorme -sobre todo por su obra poética- nunca le escuché alabar la visión borgiana del paraíso como una biblioteca y mucho menos le oi jactarse de los libros que "le fue dado leer" como presumía, con exquisita falsa modestia, el distinguido argentino. (Quizá esto se deba al hecho de que concibió la relación entre vida y literatura como un camino de ida y vuelta: todos los actos de la vida pueden conducir a un libro o a una cita como muy bien cada hoja o cada libro remite a un acto vital). Su amor por su biblioteca, como bien pronto empecé a comprender, no era el fruto de una bibliofilia o de un coleccionismo exacerbado -no habia "fanatismo" en este sentido- sino que más bien era el resultado de una íntima y muy personal relación con los libros y la literatura, con esa textura de vida que evocaba en cada libro un don. Lentamente, con esa paciencia, lentilud, y seriedad con que se debe limpiar una biblioteca aprendi en aquel conjunto de estanterías, de manera inesperada e incomprensible, me esperaba mi padre. Pronto descubrí que a pesar de mi extrema parquedad -lo que siempre desesperó a mi padre- empecé a tener algo de qué conversar con él mientras duraba aquel desempolvar de libros, ya que al volver a casa después de trabajar preguntaba con interés conmovedor por los avances del día, premiando el trabajo con alguna sabrosa anécdota sobre el origen de algún libro o sobre alguna de las insospechadas sorpresas que se podían encontrar en ellos, desde cartas y billetes de tren hasta folos, dinero y dedicaciones entrañables.

No tardé en comprender que para mi padre su biblioteca era obra y vida y que la tenía delante de mí. Antes que como escritor y como edilor su biblioleca le pertenecía como un lector, como un conjurado de la literatura, como un participante activo de la urdimbre de vida, memoria y palabra que se desenvuelve en la inagotable e incesante conversación de la que participamos mediante la literalura. Detrás de cada libro una conversación una pequeña historia que podía empezar con los delalles de su adquisición -no siempre sencillos y en algunos casos, a decir verdad un tanto extraños- y que podía acabar con la encarecida recomendación de su leclura. Empezaba así a reconocer al escritor y al hombre en sus libros, en sus lecturas.

Lo más notable es que aquellas lecturas estaban estrechamente vinculadas al mundo de la vida al que se integraban amistosamente en una forma de vivir la literatura como prodigio de alteridad que, lejos de silenciar y secuestrar a los hombres en su lectura, les animaba a revivirlas y recrearlas activamente de for- 
ma dialogada y compartida. Así su biblioteca era, más que un conjunto de libros, la textura de una vida intensa, en la que se podía detectar los hilos de su persona y de una forma de encararla de la que me gustaria hablar a través de tres anécdotas que creo reproducen esta vivencia integradora de vida y literatura.

Existía una sección en aquella biblioteca que mi padre llamaba la de libros dedicados. Se llamaba así porque en ella se colocaban los libros obsequiados y dedicados de puño y letra por alguien estimado, y en ocasiones por su propio autor. No era muy numerosa, y de hecho, su propia existencia dentro de la biblioleca era en realidad un capricho de mi padre, siendo considerable el trabajo que daba. No por la limpieza que requería, puesto que al ser pocos los volúmenes que la componían no era ésta una tarea especialmente fatigosa, sino porque la existencia de esa sección implicaba un rastreo constante de entre todos los libros para ir recuperando los libros dedicados. De esta manera, al conjunto de procedimientos de la limpieza había que añadir los de la búsqueda constante de estos ejemplares: es decir, la solapa de cada libro debía ser inspeccionada por ambas caras para su comprobación. Además esta búsqueda no se dio nunca por terminada ya que mi padre siempre albergaba sospechas de que "faltaban" libros con dedicatorias. Siempre pensé que insistía en este punto sólo para que no desistiera de buscar y para colorear la limpieza con un punto de suspense. Sin embargo, no siempre era así. A veces aparecían aquellos objetos, incluso los más inverosímiles. Como aquella dichos -y esta era la palabra clave- extraviada carta que mi padre aseguraba que Aleixandre le había escrito tras la publicación de su primer libro de poesía en Madrid. (Yo, he de reconocerlo, tenía mis dudas de su existencia... Ahora hasta me complace imaginar que durante su estancia universitaria en Madrid pudo haber conocido al poeta en su casa de Velinglonia 6, abierta a todos los poelas, sobre todo a los latinoamericanos).

Sin embargo, nunca lo vi tan alegre como cuando el azar, asistido por la diligencia, hizo aparecer un ejemplar de los "Cuentos de Cipotes" de Salarrué, edilados por la Dirección de Publicaciones en 1974 con los primorosos dibujos de su hija Maya Salarrué. Espero no errar en este punto pero creo que el libro no estaba, de hecho, dedicado a él sino a mi hermana Silvia, a la que Salarrué tan literaria y amistosamente gustaba llamar "Italina". Evidentemente no era el autógrafo que mi padre apreciaba, era esa integración de Salarrué como un abuelo Jiterario lo que tanto significaba para él. (Fue literalmente una verdadera fortuna que el libro pudiese contarse entre los autógrafos pues era un libro del que había dos ejemplares y en este caso lo habitual era destinar uno de los dos a la sección de "repetidos", lo cual habría sido una verdadera ironía pues el libro era realmente único.)

A nadie escapa que Salarrué sería un abuelo que todo el mundo quisiera para sí y para sus hijos. Esto no hace falta explicarlo. Pero es que además en aquel retrato del cipote urbano de la primera mitad del siglo, reconocía mi padre, 
criado lejos de la figura patema -y quizá precisamente por eso con mayor clarividencia- la mirada cariñosa de un observador adulto de su niñez. Supo realmente ver en Salarrué al verdadero padre literario de toda una generación de cipotes anterior a la segunda guerra mundial y a la que él pertenecía. No es de extrañar pues, que a principios de los años setenta mi padre urgiera a Salarrué para que recopilara estos cuentos dispersos, originalmente aparecidos en el Diario Patria, en solo volumen que acabaría siendo "Cuentos de Cipotes" tras una ardua labor de recuperación del material original. Había en aquella empresa de recuperación, además del evidente interés literario y editorial, una expresión profunda de gratitud casi filial hacia Salarué, cuya fama como escritor estaba fuera de toda discusión pues por aquel entonces ya había publicado 0 'Yarkandal y Cuentos de Barro. Esta gratitud se mantuvo a lo largo de loda su vida, acrecentándose aquellos tintes de gratitud filial, cuando este acogió cariñosamente a la creciente familia de mi padre: primera mi madre, y luego la prole encabezada por la Italina. Algún recuerdo directo guardo de todo ello, sobre todo de las angustiosas visitas durante su fatal enfermedad.

En una postrera edición de "Cuentos de Cipotes" que corrió a cargo de UCA editores, señalaba mi padre, evocando las propias palabras de Salarrué: "... estos relatos de niños no son para niños sino de niños para mayores de edad". No cabe duda de que los cuentos eran para él pura nostalgia infantil, lo que no significa que fuesen indulgentes o blandos pues en ellos va implícito el mensaje de "mantener el espíritu y la mente joven, abierta, receptiva, con la inocencia y la pureza de los propios niños", un mensaje formativo que era comparable al de las novelas de Dickens y las aventuras de Mark Twain que tanto quería mi padre. Esta nostalgia activa tenía un significado especial en la medida en que el mundo de aquellos cipotes, esa pureza casi poética, no murió con Salarrué, sino que pervivió y todavía produjo nostalgia: algún cuento de cipote he escuchado ya muerto Salarrué, y en uno de ellos tomaba un destacado papel mi padre.

Fue de Waldo Chávez Velasco de quien escuché este último cuento de cipotes en el que se fundía una íntima gratitud fraterna y un reconocimiento mutuo en aquel mundo. Parece ser que contando ambos con no más de diez años de conocieron tras una entrega de premios de poesía infantil patrocinada por El Diario de Hoy a instancias de su entonces direclor, Napoleón Viera Altamirano. En aquel momento ambos decidieron formalizar su amistad como jóvenes miembros del Parnaso emplazándose a escribir un poema e intercambiarlo, prestando juramento solemne de que cada uno juzgaría con la debida severidad y honestidad la poesía de cada cual. Para que la libertad de opinión no quedase coartada sobre los poemas ajenos, concertando a la vez el lugar y la hora en que se intercambiarían aquellos juicios poéticos. Detrás de un árbol, los dos "cipotes" se intercambiaron los papelitos en los que Waldo e Ilalo había escrito respectivamente: "La poesía de Italo es Bayunca", "La poesía de Waldo es Bayunca". Cuenta Waldo que rompieron de inmediato a reír a carcajadas hasta que les 
brotaron las lágrimas. Tras las risas se conjuraron para no escribir poesía hasta no haber leído y cultivado las reglas de aquel arte.

Tengo por cierta esta simpática anécdota de Waldo que sintió la urgencia testimonial de contámosla recién muerto mi padre. Estoy convencido de que quería enjugar aquel fratemal mundo literario que compartió con mi padre y que le acompañaba con Salamué de forma vital y constitutiva, y que suplió y complementó el mundo afectivo de mi padre hasta su muerte. Es cierto que la inventiva de los poetas es muy grande, ya decían los antiguos aquello de "mucho mienten los poetas", sin embargo, estoy seguro de esto: no hay mentira en esta anécdola -así lo testimoniaba la congoja de Waldo- pero sobre todo habian en ella toda la verdad, la pureza y poesía de un cuento de cipotes.

\section{II}

Una tarea que siempre encontré particulamente penosa de la limpieza de la biblioteca era la de determinar si un libro se encontraba adecuadamente clasificado, lo cual no ocurría con demasiada frecuencia ya que, por lo general, el orden de la biblioleca era bastante estable. Sin embargo, siempre topaba uno con algún incómodo ejemplar que lo hacía dudar. En ocasiones esto se debía a cierla arbitrariedad en los criterios clasificatorios, como aquel capricho que sentía mi padre por mantener unidas colecciones de libros aún a expensas de cierlas dificultades: así su empeño por mantener unida la colección de clásicos Aguilar emparejaba, no digo que desacerladamente, la obra completa de Shakespeare con la de Calderón y la de este con Dostoievski. Nunca desprobé aquella decisión pues el cuidadoso tratamiento que recibían los Clásicos por parte de Aguilar era motivo suficiente para mantenerlos agrupados. Sin embargo, el manejo de la biblioteca exigía lener presentes estas claves ya que de lo contrario uno podía preguntarse cómo era posible que en la sección de Literatura inglesa no hubiese ninguna obra de Shakespeare. Casi siempre los problemas surgidos con un libro requerían de una consulta con la enciclopedia, la que cariñosamente llamábamos "mata-burros", y que constantemente me hacía ver la agudeza de un amigo de mi padre que hablaba del "carácter enciclopédico de la ignorancia". Muchas veces el sentido común no servía de nada y en ocasiones sólo producía perplejidad como cuando uno, al limpiar la sección de teatro español, encontraba a un señor con un apellido tan poco hispánico como Hartzensbusch, entre Zorrilla y el Duque de Rivas. Por mucho que inmediatamente el sentido común me llevara a la conclusión de que el libro estaba mal clasificado la experiencia me enseñó que lo mejor era no precipitarse en ningún caso; una consulta a tiempo con el mataburtos era la mejor manera de evitar que fuese mi padre cl que me invitase a su consulta, no sin antes recordarme aquello de que los libros no deben evaluarse por las tapas... 
Sin embargo, las dificultades de la taxonomía bibliotecaria no siempre se podían resolver acudiendo al "mataburros", o localizando las colecciones de libros más queridas por mi padre. Muchas veces eran los propios libros y su propia ambigüedad, los que se convertían en verdaderos enigmas. Tal era el caso de un ejemplar de Juan Ramón Jiménez que ahora tengo delante de mí, su tílulo: Platero y Yo. Trescientos poemas. (1903-1953). Se trata de una popular edición de la editorial mexicana Porrúa lanzada como parte de la colección "Sepan cuantos...", que mi madre me había dedicado y regalado unos años atrás, como un estímulo para la lectura infantil tras haberle comentado que en el libro de lectura del colegio habíamos leído algo sobre un borriquito. Fue por eso que cuando lo localicé entre los libros de poesía española entendí que se trataba de un error: el libro tendría que figurar en la sección de cuentos o relatos cortos. (No había aquí confusión posible pues la humildad y la disparidad de esta colección ("Sepan cuantos...") no aconsejaba su agrupación; y en cuanto a lo de ser un libro dedicado, tampoco se aplicaba ya que la cercanía de quien lo regalaba era demasiado evidente.)

No reparaba en el hecho de que su título completo hablaba de "Trescientos poemas". De hecho, ni siquiera era muy consciente de este pequeño detalle ya que me parecía incuestionable que Juan Ramón Jiménez era "sobre todo" conocido por ser el autor de Platero y Yo. Cuando orgulloso de mi descubrimiento lo puse en conocimiento de mi padre, pude notar que aunque procuró resultar comprensivo no estaba dispuesto a ceder a la hora de llevar este autor a las provincias de la prosa; y mucho menos a ser cómplice de la inintencionada y natural tendencia de los maestros de colegios a trivializar, despoetizar e infantilizar su obra. Clausurada la cuestión por el poderoso argumento de autoridad, volví a colocar aquel libro -que era mío- en su sitio. De todas formas nunca comprendí que permaneciese clasificado como poesía.

Al poco tiempo, emprendió mi padre una de aquellas "campañas" de "culturización poética" en las que procuraba cultivar nuestro amor por la poesía haciéndonos aprender de memoria algún verso sencillo. Creo recordar que en aquella ocasión escogió a Bécquer, uno de aquellos escritores de cuyo apellido no podía uno fiarse a la hora de encontrar su sitio en la biblioteca. Escogió uno de sus poemas más conocidos, uno que con loda probabilidad figuraría en cualquier manual de los cursos de literatura que acabaríamos por leer a lo largo de la secundaria. Si por ventura alguien recuerda un verso de Bécquer, lo más probable es que sea aquel que dice: "Volverán las oscuras golondrinas...", y quizás fue precisamente por eso que mi padre se anticipó a aquellos apremiantes cursos de literatura en lo que lo sencillo corría el peligro de convertirse en trivial y banal. (Quizás tuviese en mente el peligro de que ocurriese con Bécquer, lo que podía ocurrir con la "pureza" poélica de Platero tan relacionada con la del primero). 
La irritación de mi padre era mayúscula si nos limitábamos simplemente a repelir desganadamente el poema. Sin embargo, creo que secretamente cra esto lo que más le guslaba. Era enlonces cuando dejaba de "Iomarnos la lección": tras proferir algunas palabras condenatorias de la apatía y de la falta de respeto por la poesía, pasaba a indicarnos cómo debía recitarse. No es que fuese un gran declamador, pero se podía apreciar con toda claridad la emoción y el entusiasmo que sentía por la forma y el rilmo que evocaba con la palabra. Tras aquellas demostraciones no había quien pudiera dudar de la belleza de la poesía y desde luego de la solemnidad de este poema -que seguro habría perdido en aula de secundaria- había quedado a salvo. Pero había algo más que pedagogía en aquellas sesiones.

En general, era muy raro escuchar a mi padre hablar sobre literatura, mucho menos de poesía. Tenía un pudor y una aversión a la banalización de la literatura extremas, razón por la que la escondía y administraba celosamente. Casi se podría decir que en él, la literatura vivía secuestrada en la "Irastienda interior del alma" como un pequeño retal cuyo valor reside precisamente en permanecer retirado, en permanecer como un "horizonte recogido sobre sí mismo", que sólo merece ser desplegado en el contacto más íntimo. No hace mucho tuve noticia de que en al menos otra ocasión desplegó aquella pasión por la musicalidad de Bécquer. Y lo hizo muy en consonancia con esa vivencia literaria interior que del poeta tenía, pues Román Mayorga Quirós -ex-reclor de la UCA y gran amigo suyo- no hace mucho que evocaba en un caluroso texto aquella ocasión como un momento lleno de poesía:

"En aquellos años comunes en la UCA la amistad mía con ltalo se hizo más honda y permanente. Nos veíamos con gran frecuencia, dentro y fuera de la universidad, y a veces almorzábamos a solas. Nos gustaba especialmente hacerlo al aire libre, en medio de los árboles. En el jardín de mi casa había un muro de ladrillo rojo en el que estaban empolrados, como decoración, dos balcones españoles antiguos llenos de geranios. Italo mencionó en uno de nuestros almuerzos "esos balcones tuyos que no dan a ninguna parte"; hizo una pausa y me soltó una lección magistral sobre la poesía de Bécquer que, según descubrí entonces, el conocía perfectamente y gustaba mucho de ella. Luego habló de las "golondrinas" de sus propios versos... Esa tarde advertí que su poesía era el refugio de su propio yo... En ninguna otra ocasión escuché a ltalo recitar delante de nadie".

Buena parte de la poesía de aquel momento debe atribuirse a la calurosa amistad y sensibilidad de Román Mayorga, quien ha sabido extraer de aquella ocasión un logrado ejemplo de memorialismo a la vez que ha correspondido noblemente a su amistad con mi padre y con su poesía. Debo agradecerle que, aunque él no lo sepa, sea un cómplice personal de la vivencia poética de $\mathrm{mi}$ padre, que fue la que a mí me hizo intuir en qué consistía la pọesía. $O$ al menos 
la suya, la que compartía con Bécquer, Cernuda, Darío y, como no, Juan Ramón Jiménez.

Tuve conocimiento de este texto de Román Mayorga a través de mi madre, quien me mandó fotocopias del libro litulado: "Recuerdo de Diez Quijotes". En la fotocopia inicial, que en realidad corresponde a la contraportada del libro, hay una anotación de mi madre -su letra emborronada de médico es inconfundibleen la que se lee algo así como "Para Italo". No es una dedicatoria sino más bien una indicación pues creo recordar que en el paquete en que venían esas folocopias había algunas cosas que no estaban destinadas a mí. De todas formas, aquella anotación me hizo recordar aquel ejemplar de Platero y Yo, en cuyo "Prologuillo" hecho por el propio Juan Ramón se puede leer: "Este breve libro, en donde la alegría y la pena son gemelas, cual las orejas de Platero, estaba escrito para... ¡Qué se yo para quién!... para quien escribimos los poetas líri$\cos$... Ahora que va a los niños, no le quito ni le pongo una coma". Un poco después el poeta niega el carácter pueril del libro y dice con toda claridad: "Yo nunca he escrito ni escribiré nada para niños"; y tras haber señalado que él no reniega de la pureza espiritual que puede hacer de su libro una leclura para todos, niños o adultos, insiste en la idea de que: “'Dondequiera que haya niños dice Novalis-, existe una edad de oro'. Pues esa edad de oro, que es como una isla espiritual, anda el corazón del poeta..."

Ahora comprendo mejor aquella ubicación de "Platero", tan cerca de Bécquer, y ahora comprendo por qué este libro tenía su lugar entre la pura poesía tan lejos de la puerilidad de los serios.

\section{III}

Como toda biblioteca que se precie de serlo la nuestra tenía su Quijote. Bueno, en realidad tenia varios, puesto que entre ediciones infantiles y no tan infantiles podría haber hasta tres. Sin embargo, el Quijote de aquella biblioteca era un amarillento libro viejo de varios volúmenes, con una encuademación aguamarina y con un fuerte olor a libro añejo. (Es posible, considerando el libro en retrospectiva, que este fuera un ejemplar de la edición de 1874 de Rivadeneyra que corrió a cargo de Juan Eugenio Hartzenbusch y para la que Gustavo Doré realizó sus dibujos originales). Sin embargo, nunca llegué a leer aquella edición. Tomé el camino que correspondía a mi edad y mi primer contacto con el Quijote fue a través de alguna edición infantil ilustrada puerilmente y que no merece ser recordada por nada en especial.

No obstante, la fuerte personalidad de aquel libro y su presencia dominante en la estantería siempre atrajeron mi atención mientras cumplía con mis tareas de limpieza. Un libro así reclamaba un alto. Recuerdo que me gustaba observar aquellas bellas láminas de Doré que me producían un estupor a medio camino 
del miedo y de la risa, y que era fácil ver que ilustraban olra cosa muy distinta de lo que yo podia leer en mis versiones infantiles.

El mayor motivo de aquella risa inocente era el enorme parecido físico entre el Quijote de Doré y Don Hugo Lindo, un viejo y querido amigo de mi padre al que frecuentaba en compañía de toda la familia. Este parecido era evidente hasta para el propio Don Hugo que con su desbordante sentido del humor lo adoptaba como parte de su vivencia literaria del mundo. Estoy casi convencido que le agradaba exagerar y potenciar este parecido, pues sentía tal afecto por el personaje de Don Quijote y por el de Cervantes, que al oírle recitar en tono burlesco la descripción inicial del Quijote no era difícil creer que se identificaba, de buen grado, con aquello de "seco de carnes, enjuto de rostro", así como con aquel irónico autorretrato cervantino en el que se habla de una "boca pequeña, los dientes ni menudos ni crecidos, porque no tiene sino seis y esos mal acondicionados y peor puestos". (Aunque llevaba con una elegancia soberbia sus dientes postizos le encantaba en la intimidad gastar bromas sobre su aspecto desdentado pese a la desaprobación de su encantadora mujer, Carmencita). Compartía plenamente este humor cervantino con mi padre al que solía recibir en su casa bajo la cómica y ceremoniosa fórmula de "Mi querido don Italicus' a lo que mi padre solía contestar algo así como "mi estimado Don Hugo", y en algunas ocasiones incluso "Caballero de la triste figura". Estos saludos iban acompañados de una bufonesca e irreproducible prosodia y entonación caballeresca. (Lo de Don Italicus, por otra parte, venía de una celebrada broma de Don Hugo, quien trajo de España un cartel de corridas de toros, que son copia de los auténticos, y que se ofrecen como suovenir a los turislas quienes pueden completar el elenco de toreros con el nombre que ellos elijan. Quiso Don Hugo que compartiera cartel Italo López Vallecillos, "Don Italicus", con Paco Camino y con Manuel Benítez, "El Cordobés", lo que hizo a mi padre reír durante muchos años).

Aparte del fino humor cervantino de Don Hugo, con el que tan bien sintonizaba mi padre, compartían ambos una gran admiración por los clásicos del Siglo de Oro que en el caso de Don Hugo era patente en su propia creación literaria como lo atestigua el tílulo de una de las novelas salvadoreñas más destacables de este siglo: Justicia, señor gobernador, que como es bien sabido procede del Quijote. Esta admiración compartida por los clásicos evitaba la pedantería puesto que, a pesar de ser sobre todo una admiración por la pureza del lenguaje, era la reciedumbre del idioma la que salía siempre triunfante. Además se redimía por la propia burla en la que surgía. No había en ella nada de pacato, ni de elevado y se servían de ella jocosa, abierlamente y con una naturalidad desconcertante para reírse de todo. Como cuando mi padre, tras notar que enjugascados nos excedíamos en chillidos al jugar, nos llamaba al orden delante de Don Hugo con los versos iniciales del Don Juan de Zorrilla: “¡Cuál gritan esos maldilos!/ ¡Pero, mal rayo me parta/ si en concluyendo la carta/ no pagan caro sus gritos!". O como cuando a carcajadas reían las gracias de Quevedo del "señor ojo del 
culo" con una procacidad calculada para escandalizar a alguna refinada visita. $\mathrm{O}$ como cuando se desternillaban de la risa con alguna de las más jugosas entradas del Diccionario Secreto de Camilo José Cela delante de un grupo de familiares. Todo aquello en sí mismo, no era más que literatura, una competencia de ingenio, un efectismo de palabras divertidas. Lo realmente importante era esa experiencia compartida de los clásicos y la literatura como una redención de las miserias propias y ajenas, a través de la risa, el humor y la fantasía. Es difícil describir hasla qué punto su amistad y su propia constilución personal estaba permeada por ese exorcismo conscientemente compartido, constante, agudo e inteligente de las debilidades y faluidad del mundo.

En realidad, y a pesar de las apariencias, había muy poco del pobre Don Quijote en Don Hugo y, mucho menos, en mi padre. En cambio lo que si había era mucho cervantismo, es decir una templada y compleja relación con la literatura, los libros y la realidad en la que el cultivo afilado de la palabra para reírse de lo ridículo, lo maniático, lo falso y lo afectado constituye el principal mensaje vital. En el cultivo de ese difícil arte, se ejercitaban y se complacían en juegos de la imaginación deliberadamente absurdos, propios de un cervantismo indirecto como el de los personajes de Sterne. Buen ejemplo de ello era aquel proyecto de una imaginaria Real y Pontificia Academia de la Lengua Viperina en la que figuraban prominentemente ambos, aunque no sé muy bien en que orden, como "Excmo. Sr. Director ad perpetuam y ex-ofidio" y como "Excmo. Sr. Secretario ad-horrorem et bífido". La clave de este amable dislate era muy simple: se trataba de una forma de expiación de sus "pecadillos" deslenguados; se trataba de una broma que se gastaban a sí mismos por su tendencia a irse de la lengua al criticar a algunos personajes del mundo literario y académico de El Salvador. Las licencias irónicas que se atribuían en su condición de "académicos viperinos" era muy clara; tras identificarse como deslenguados -salvándose así de cualquier hipocresía- procedían a regodearse en sus ocurrencias.

Para quien no lo conoció esto parece esconder alguna maldad o misantropía practicada por maledicentes y por personas realmente viperinas. Nada más lejos de la realidad. Es cierto que jugaban a burlarse de la inevilable pompa que podía haber en la Academia, y además -esto no debe olvidarse- de su propia condición .de académicos; pero lo hacían con un humor acerado que no prelendía ninguna maldad sino una saludable crílica salpicada de pimienta. No había agresividad en ello son un alegre y recio cervantismo.

Un moralista francés, partidario de las virtudes morales de la ironía, aprobaba las palabras de un hombre ingenioso al que había oido decir: "Arrebatad a la ironía su imperio y abandono al dia siguiente la sociedad". Claro, que este mismo abandono supondría un ejercicio deliberado de ironía; por lo que es fácil entender que la ironia, amiga transparente de la paradoja, no se abandona tan fácilmente pues pone en marcha raros juegos que suelen invertir la lógica de las 
cosas como reafirmarlas desde su alteridad, desde su reverso. Me contaba Arturo Lindo, hijo de Don Hugo y heredero de su bonhomie, que la primera vez que vio a mi padre tras la muerte de Don Hugo esperaba algunas palabras de aliento de él, pero mi padre -consciente quizás de que su amigo cervantino le había abandonado definitivamente- abandonó toda ceremonia y exigió a Arturo que lo consolase a él, que no estaba para dar pésame sino para recibirlos. Mientras me contaba esta anécdota dudaba si había una pizca de reproche en Arturo, pues lógicamente comprendi que era posible que le hubiera disgustado aquella extravagancia de mi padre; pero, al cabo de un ralo, supe que habia tomado plenamente el pulso a este pésame cervantino, que por medio de una cariñosa pirueta y en un raro juego de alteridad; Arturo sabía muy bien transmitirme un par de días después de la muerte de mi propio padre.

Madrid, primero de febrero de 1996. 